\title{
Wo steht die deutschsprachige Allergologie im internationalen Wettbewerb?
}

W issenschaftler aus dem deutschen Sprachraum standen $\mathrm{Pa}-$ te bei der Geburt der Allergologie und klinischen Immunologie. Der Beitrag von Fuchs und Schadewaldt zu der von Prausnitz und Küstner erstmals im Jahre 1920 nachgewiesenen passiven Übertragbarkeit der Anaphylaxie zeigt dies in besonders anschaulicher Weise. Es ist beiden $\mathrm{Au}$ toren an dieser Stelle sehr herzlich für ihr Engagement für die historischen Aspekte der Allergologie zu danken, die sie seit Gründung des Allergo Journals in äußerst lesenswerten Beiträgen unterstrichen haben.

Und heute? Wie stehen wir da, verglichen mit denen, die das Fach begründeten? Im internationalen Wettbewerb hat der deutsche Sprachraum auf nahezu allen Gebieten der Wissenschaft Federn lassen müssen, nicht nur in der Allergologie und der klinischen Immunologie. Die deutsche Sprache als Wissenschaftssprache hat seither ihren Rang völlig verloren. Wer erinnert sich noch daran, daß die International Archives of Allergy and Applied Immunology und die Acta allergologica (heute „Allergy“) bis in die 70er Jahre auch deutschsprachige Artikel veröffentlicht haben?

Es ist an der Zeit, nicht der Vergangenheit nachzutrauern, sondern das Unvermeidliche zu erkennen und sich anzupassen. Daher ist es erfreulich, die zunehmende Bereitschaft jüngerer Wissenschaftler zu sehen, in ihren Lebenslauf längere Auslandsaufenthalte einzuplanen, vorzugsweise in den USA und England. Die Früchte dieser Aktivitäten sind unverkennbar, sei es durch die zunehmende Zahl internationaler Publikationen deutschsprachiger Wissenschaftler, sei es durch die erfreulich große Beteiligung an internationalen Kongressen. Auch die pharmazeutische und allergologische Industrie sorgt dafür, die internationalen Grenzen abzubauen, sei es durch Etablierung von Forschungsstätten im Ausland, durch international angelegte Studien oder durch multinationale Forschungsteams. Nicht nur der Euro steht ins Haus, auch die europäische Verbundforschung gehört zu den wenigen zukunftsträchtigen Quellen der Forschungsförderung!

Der Stellenwert der nationalen Allergologie im internationalen Konzert läßt sich am besten erkennen, mißt man die Anteile bei internationalen Kongressen. In „Zur Sache“ 7/97 dieser Zeitschrift wurde auf den alle drei Jahre abgehaltenen Weltkongreß der „International Association of Allergology and Clinical Immunology" vom 19.-24. Oktober 1997 in Cancun, Mexico, hingewiesen. Die Beteiligung war eindrucksvoll, nicht nur dadurch, daß zahlreiche deutschsprachige Kollegen vor Ort anwesend waren, sondern auch durch eine Fülle von Kongreßbeiträgen aus dem deutschsprachigen Raum. So waren unter anderem 5 der 37 Empfänger eines Travel Grants aus Österreich oder aus Deutschland. Abgesehen von einer Fülle freier Beiträge, stammten 20 von 152 Vortragenden der Haupt- und Parallel-Symposien aus deutschsprachigen Ländern.

Dennoch dürfen wir uns nicht zufrieden zurücklehnen, wenn es um den

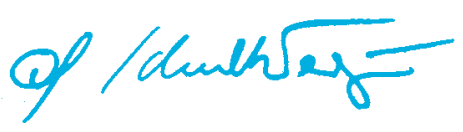

Prof. Dr. G. Schultze-Werninghaus
Einfluß auf nationaler und europäischer Ebene bei der Vergabe von Forschungsmitteln und gutachterlichen Positionen geht. Versucht man, einen gemeinsamen Nenner für den ungenügenden Stellenwert nationaler allergologischer Bemühungen um internationale Anerkennung zu finden, so landet man rasch bei zwei Aspekten. Erstens bleiben immer noch die Folgen des „Dritten Reiches“ zu bedenken. Zweitens - und speziell für die Allergologie und klinische Immunologie gültig - ist der Mangel an öffentlichem und vor allem staatlichem Interesse an Spitzenleistungen, d.h. Förderung der Eliten, spürbar, der sich in der Nivellierung der Hochschulen, dem Fehlen spezialisierter allergologischer Einheiten bzw. dem Fehlen von Lehrstühlen, der zurückhaltenden Bereitschaft für die Schaffung effizienter Forschergruppen, etc. etc., erkennen läßt.

Was bleibt? Es bleibt der Appell an die junge Generation, die Fehler der früheren Generationen zu vermeiden bzw. wettzumachen, sei es die Scheu vor internationalen Kontakten, die mangelnde Bereitschaft zu längeren Auslandsaufenthalten oder die Hemmung zur Publikation in internationalen Journalen.

Ihnen allen wünschen Verlag und Herausgeber ein geruhsames Weihnachtsfest und einen besinnlichen Jahreswechsel.

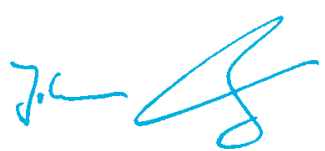

Prof. Dr. Dr. J. Ring 